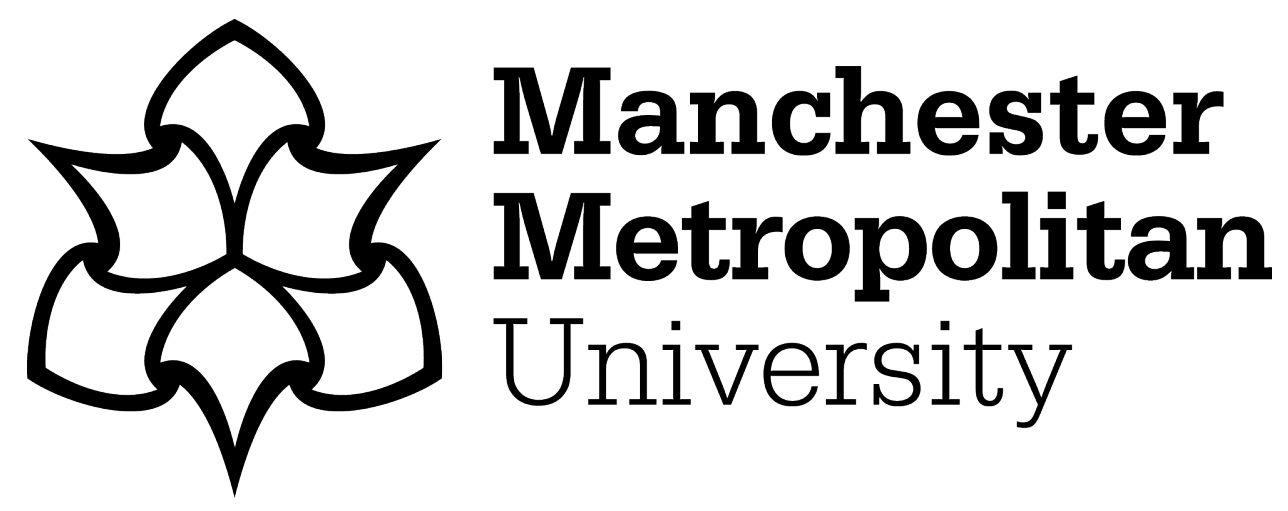

tom Dieck, Mandy ORCID logoORCID: https://orcid.org/0000-0002-87658969, Tom Dieck, D and Jung, T ORCID logoORCID: https://orcid.org/00000002-8594-6641 (2021) Exploring usability and gratifications for virtual reality applications at festivals. Event Management, 25 (6). pp. 585-599. ISSN 1525-9951

Downloaded from: https://e-space.mmu.ac.uk/624129/

Version: Accepted Version

Publisher: Cognizant Communication Corporation

DOI: https://doi.org/10.3727/152599521X16106577965152

Please cite the published version 
https://doi.org/10.3727/152599521X16106577965152

MS 19045 accepted for publication in Event Management

\section{Exploring Usability and Gratifications for Virtual Reality Applications at Festivals}

M. Claudia tom Dieck, Dario tom Dieck, and Timothy Jung

Department of Operations, Technology, Events and Hospitality Management, Manchester Metropolitan University, UK

Timothy Jung: ORCID ID: https://orcid.org/0000-0002-8594-6641

Correspondence concerning this article should be addressed to M. Claudia tom Dieck, Righton Building, Cavendish Street, M15 6GH, UK, Email: c.tom-dieck@mmu.ac.uk

https://orcid.org/0000-0002-8765-8969 


\begin{abstract}
The digital creation of virtual environments has opened many doors for the creation of new experiences, offering the trend of ever immersive, engaging and multi-sensory virtual reality (VR) experiences. However, studies on VR within the science festival context are limited. Therefore, with a focus on usability and gratifications, this study aims to explore the antecedents of the behavioral intention to use VR at science festivals. Before participating in a questionnaire, 447 users experienced a VR application and data were analyzed using structural equation modelling. Findings reveal that usability influences gratification factors which influence users' behavioral intention to engage with science.

Keywords: Virtual reality, usability, gratifications, immersion, emotions, flow
\end{abstract}




\section{Exploring Usability and Gratifications for Virtual Reality Applications at Festivals Introduction}

Virtual reality (VR) has surpassed specialist applications such as architecture, medical or military and has now entered a wide array of consumer applications including retail, tourism, gaming and education. VR is here to stay and while at the beginning expectations have been high and the reality disappointing, latest devices and software offer a promising outlook for business applications (Tredinnick, 2018). The digital creation of virtual environments has opened many doors for the creation of new experiences (Han \& tom Dieck, 2019), offering the trend of ever immersive, engaging and multi-sensory experiences (Moorhouse et al., 2019b; Rauschnabel et al., 2019). Research in the festival context has also recognized these opportunities, with a recent study confirming that interactive media helps visitors to engage with festivals (tom Dieck et al., 2018b). This was supported by van Winkle et al. (2016) who explored the use of mobile devices at festivals as part of the co-creation of value between festival goers and organizers. In their study they found that mobile phones allow for linking, building and performing opportunities, especially in terms of social media usage and the sharing of content during events as well as the possibility to stay connected. Nevertheless, research within the event context and the use of more immersive technology such as VR is non-existent. In the music festival context, Coachella tested how the provision of cardboards could enhance the immersion and engagement of festival attendees. They were able to receive $360^{\circ}$ videos of live music content as well as create their own content, which was linked to the concept of value co-creation through active engagement in the design process. In addition, non-attendees were able to engage with the content which created immersive experiences for users around the world (Atkins, 2017). 
Another popular type of festivals are science festivals which are normally of temporary nature, aiming to engage the general public in current scientific research (Jensen \& Buckley, 2014). In general, science festivals aim to engage the public to gather new knowledge and skills (tom Dieck et al., 2018b). In fact, Jensen and Buckley (2014, p. 558) argued "public engagement has become the new mantra (at least in UK and EU science policy", contributing to the trend of at least ten science festivals a year in the UK alone. Easson and Leask (2019) found that museums started to offer special events in order to attract and target new audiences and result in repeat visitations. Recently, research found that technological innovations such as augmented reality can contribute to visitors' engagement (tom Dieck et al., 2018b). Nevertheless, examples for the use of VR for the enhancement of the science festival experience is limited. Considering that numerous studies supported the use of VR for educational purposes (Hodgson et al., 2019; Huang et al., 2018), its use for science festivals seems a natural development. In fact, "although first studies have been conducted early, there are few empirical findings shedding light on issues of acceptance and use of VR" (Mütterlein \& Hess, 2018, p. 1). Specifically, studies supported VR's strength in terms of enjoyable and flow experiences (Huang et al., 2013).

Huang et al. $(2013$, p. 497$)$ investigated the acceptance of second life and found that hedonic factors including enjoyment, emotions and flow influence behavioral intentions and called for further research to "investigate other important predictors that can influence hedonic consumption behavior". Furthermore, immersion is hereby considered one of the most important factors for VR adoption according to Shin (2017). However, immersion has so far received limited attention within the context of VR adoption. Utilitarian benefit factors are drawn from the technology acceptance model (TAM), the leading theory of adoption, while affective needs factors come from the uses and gratification theory (U\&GT), suggesting that technology is used 
when it provides pleasurable experiences. This study adopted the integrative model of TAM and U\&GT which was used in several previous studies. For instance, Hayashi et al. (2004) revealed the positive relationship between perceived usefulness and satisfaction in on-line training environments and Rai et al. (2002) found that perceived usefulness and perceived ease of use influence on user gratification. Furthermore, Shin (2009) empirically showed that consumer gratification is impacted by perceived usefulness and perceived ease of use in mobile commerce. Shin (2011) also found that perceived ease of use and perceived usefulness were significant antecedents of e-book users' gratification.

Previous studies have found that hedonic attributes with regards to devices and applications are closely linked to usability (Han et al., 2018). When it comes to the use of VR, although this new media is becoming widely used in various different contexts, it is unknown what are the motivations to use VR and how these influence affective needs, such as enjoyment, emotions, flow and immersion, and eventually lead to behavioral intentions to use VR. Particularly the event and festival context has so far received limited attention with regards to how technologies could enhance the visitor experience, nevertheless it is offering festival goers novel experiences by adding value through a co-creation of experiences (van Winkle et al., 2018). To address this gap in the literature, this study examines usability factors (perceived ease of use and perceived usefulness) as the antecedents and gratification factors (affective needs) as mediator and behavioural intention as a consequence within the science festival context using a U\&GT.

\section{Hypotheses Development}

\section{Usability}

Perceived ease of use (PEU) and perceived usefulness (PU) stem from the TAM developed by Davis. Those two determinants of technology adoption have throughout the years 
been extensively tested and confirmed as main usability indicators of why people accept or reject technologies (Davis et al., 1989; Kim et al., 2008a). However, interestingly van Winkle et al. (2019) reviewed technology adoption studies within the events and leisure context and concluded that there is limited research focusing on the acceptance of mobile services and related applications within the aforementioned context. They also revealed, that if designed and implemented correctly, useful and easy to use devices and applications can add immense value to the festival experience (van Winkle et al., 2018). Shin and Biocca (2017, p. 67) defined PU as the degree of which a technology is "capable of being used advantageously". This slightly differs from earlier definitions, which focused on workplace technologies and therefore included the enhancement of work performance. Nonetheless, with today's adyancements, technologies are supposed to offer frictionless services thus, the current study proposed that PU, although extensively tested, is still immensely relevant for today's VR context.

PEU is defined as the degree of which people perceived that using a technology is free of effort and simple to understand (Raza et al., 2017). Keeping complexity low is considered key in order to enhance acceptance of a technology as shown by a number of studies (e.g., Chong et al., 2012). Throughout the years, the majority of TAM studies found that PEU influences PU (e.g., Nysveen et al., 2005; Pavlou (2003); tom Dieck et al., 2017) and therefore, the following hypothesis is proposed.

H1a: Perceived ease of use has a positive relationship with perceived usefulness In addition, numerous studies supported the effect of PEU and PU on mediating variables such as enjoyment, risk or discomfort (e.g. Saade \& Bahli, 2005; Teo \& Noyes, 2011; Venkatesh, 2000). However, according to tom Dieck et al. (2017), mediating variables are context specific and therefore, it is important to evaluate the effects PEU and PU have on VR- 
specific variables. In the context of the current study, usability's influence on U\&GT constructs, as previously supported by Shin $(2009 ; 2011)$, is suggested. Shin $(2011$, p. 265) revealed that "there is a positive correlation between perceived usability and gratification". Therefore, the following hypotheses are proposed:

H1b: Perceived ease of use has a positive relationship with enjoyment.

H1c: Perceived usefulness has a positive relationship with enjoyment.

H1d: Perceived ease of use has a positive relationship with emotional involvement.

H1e: Perceived usefulness has a positive relationship with emotional involvement.

H1f: Perceived ease of use has a positive relationship with immersion.

H1g: Perceived usefulness has a positive relationship with immersion.

Finally, Wu and Wang (2005) posited that PU influences the behavioral intentions to use mobile commerce. Similarly, Venkatesh (2000) confirmed that PU is a much stronger predictor of behavioral intention than its counterpart PEU. In addition, also Pavlou (2003) only found PU to influence behavioral intention. Consequently, the current study proposes that:

H1h: Perceived usefulness has a positive relationship with behavioral intention.

\section{Uses and Gratification (U\&GT)}

The U\&GT is grounded in human communication research and proposes that "audiences consciously choose the medium that could fulfil their needs and that they are able to recognize their reasons for making media choices" (Shao, 2009, p. 8). In principle, it is suggested that people use media in order to satisfy needs such as enjoyment, socialising or flow experiences (Rauschnabel et al., 2017). In addition, U\&GT aims to explore motives and identify consequences that follow from those aforementioned needs. Overall, it is anticipated that psychological needs result in certain expectations (behavioural intentions) of media usage (Chen, 
2011). To narrow it down, this study focuses on affective needs of users to use VR. Rauschnabel et al. (2017) revealed that affective needs are a combination of emotions, pleasure, as well as moods that consumers want to obtain. Considering that the TAM has a strong focus on usability factors, an integration of these two theories is aimed to deliver important implication on behavioural intentions of VR use. The inclusion of U\&GT is particularly important considering the immersive and engaging nature of VR, where hedonic factors play a vital role of the entire experience (Jung et al., 2017).

Enjoyment. Enjoyment is the degree to which users perceive experiencing a VR application as enjoyable.

According to Rauschnabel et al. (2017), enjoyment has been thoroughly applied in the U\&GT context and was found to strongly drive the use of technologies. Especially, more recently they found that it influences the motivation to play AR games. Enjoyment was included in the latest VR adoption model proposed by tom Dieck et al. (2018a) in the national park context. Enjoyable applications are expected to influence the emotional involvement, overall emotions as well as the perceived flow. Wu and $\mathrm{Lu}$ (2013) conducted a meta study on intrinsic motivators and found that the majority of studies usually supported the effects of intrinsic motivations (e.g., enjoyment, playfulness, pleasure) on positive emotions. In addition, within the education context, Hernik and Jaworska (2018) confirmed that enjoyment positively influences emotional involvement and the willingness to learn new things. Also within adoption studies, enjoyment was found to influence, for instance, flow (Kim et al., 2018). Therefore, the following hypotheses are proposed:

H2a: Enjoyment has a positive relationship with emotional involvement. H2b: Enjoyment has a positive relationship with positive emotions. 
H2c: Enjoyment has a positive relationship with flow.

Emotional involvement. Särkelä et al. (2004) defined emotional involvement as the degree of intensity and quality of experiences. The link between emotional benefits and VR was recently made by a study on user adoption (tom Dieck et al., 2018a). Campos et al. (2004, p. 379) aimed to define emotions and suggested that emotions are "the process of registering the significance of ... an event ... [while] the nature of significance ... determines the quality of the emotion. According to Rauschnabel (2018), people use certain media in order to experience emotions. With this line of thought, the importance of emotional involvement as part of technology adoption becomes apparent. The experience economy had a similar concept, in that it advocates that consumers are no longer interested in simply consuming products or services. Instead, the modern consumer wants to be involved in the co-creation process thus, create an emotional involvement (Jung \& tom Dieck, 2017). Consequently, it is believed that emotional involvement creates overall positive emotions but also, optimal (flow) experiences. Therefore, the following hypotheses are proposed.

H3a: Emotional involvement has a positive relationship with positive emotions.

H3b: Emotional involvement has a positive relationship with flow.

Immersion. According to Shin (2017), the concept of immersion is most commonly known within the gaming and virtual environment context. Immersion is the "Psychological state characterized by perceiving oneself to be enveloped by $[\ldots]$ an environment that provides a continuous stream of stimuli and experiences" (Witmer \& Singer 1988, p. 227). Mütterlein and Hess (2017) found that although one of the most important constructs of VR adoption, it has so far been neglected as part of VR user-centric research. Immersion as part of VR is linked to the quality of the hardware and software design as well-designed applications are generally 
perceived to be more immersive (Laver et al., 2015). In addition, immersion is linked to users' ability to immerse themselves in a digital environment full of imagination, exploration and adventure, essentially blurring the lines between reality and virtuality (Lee et al., 2020; Shin, 2017). The connection between immersion and positive emotions has, according to Peilloux and Botella (2016), been long established. For instance, Shaw (1989) revealed a positive relationship between immersion and positive emotions for creative thinking within science and engineering. In addition, fully immersive applications are expected to erect positive emotions and result in an optimal experience, linking to flow (Mütterlein \& Hess, 2018). Therefore, the following hypotheses are proposed:

H4a: Immersion has a positive relationship with positive emotions.

H4b: Immersion has a positive relationship with flow

Positive emotions. Fredrickson et al. (1998) proposed the "broaden-and-build theory of positive emotion", exploring the concept of positive emotions and its effects on behavioural intentions. It stems from the medical discipline where positive emotions have shown to produce faster recovery from surgeries and illnesses. Linking it more to the VR context, positive emotions are believed to broaden the thought and action repertoire, consequently a joy of using VR might produce a general desire to play, visit environments or change behaviors (Waugh \& Fredrickson, 2006). This was also confirmed in the festival context, where van Winkle et al. (2019) were the first to explore the adoption of mobile services. Their study revealed that hedonic motivations influence behavioral intentions. Therefore, the following hypothesis is proposed:

H5: Positive emotions has a positive relationship with behavioral intention.

Flow. Holsapple and $\mathrm{Wu}$ (2007) were one of the first to introduce the concept of flow into VR experiences. According to the flow theory, users experience a sense of flow when they 
engage in activities that fully challenge their skills, while not overwhelming them. The idea of flow is linked to the "ideal" experience and theorized to enhance user behavioural intention to use technology (Bachen et al., 2016). Shin (2017, p. 6) summarized flow in one sentence and found it to be "a complete absorption in the activity that one is involved and the loss of one's sense of space and time". Chen et al. (2018) looked at the flow theory from a marketing perspective and confirmed that the more customers gain pleasure from using services, the more likely they are to have favorable opinions and behaviors towards said service. Rauschnabel et al. (2019) furthermore confirmed that flow influences behavioral intentions to engage with content and services. Thus, we propose the following:

H6: Flow has a positive relationship with behavioral intention.

Based on the hypotheses, Figure 1 presents the proposed model.

\section{$<<<$ Insert Figure 1 here $>>>$}

\section{Methods}

\section{Study Context}

The study was conducted as part of the European City of Science festivities in Manchester in the summer of 2016. According to Jensen and Buckley (2014), science festivals use alternative forms of public engagement including fairs, scientific kiosks, lecturers, workshops and demonstrations and exhibitions. As part of the European City of Science public engagement project, a VR application was offered under the idea of scientific kiosks whereby pop-up stalls were located around the city of Manchester (see Figure. 2). Participants were asked to experience the VR application and participate in this study as part of a festival display in a major shopping centre in Manchester. During the week of data collection in July 2016, a number of festival related activities took place in the shopping centre in order to promote and show case 
Manchester's science. For the purpose of this study, a VR application was developed using 360degree content about science related content. One example included VR content on the cancer research UK facilities whereby participants could take a journey through part of the laboratory while it was in operation, an area not normally open to the public. Another scenario was centred around the Jodrell Bank Observatory. In this instance the application let participants experience the third largest steerable radio telescope in the world and how it completes a 360 degree turn in the course of a about 30 seconds; a process that normally takes an entire day. Ethical approval was obtained and due to the nature of the study, only users above the age of 18 and without any health related problems were allowed to participate.

\section{$<<$ Insert Figure 2 here $>>$}

\section{Data Collection}

Data were collected in July 2016 at one of the major shopping centres in the city (see Figure 2). Due to the nature of the project, offering the VR science experience to the general public, a convenience sampling was chosen. Prior to completing a questionnaire, participants experienced the VR application which lasted around five minutes. The questionnaire consisted of two sections. The first section focused on the seven factors which were measured by three to four measurement items, adopted from previous research (please refer to appendix). The second section inquired about participant's characteristics as shown in Table 1. 447 usable data were collected. The majority of participants was aged between 18 and 34 and earned less than $£ 40,000$. More than $40 \%$ of participants were full time employed, while $20 \%$ were students. Considering Manchester as a student city, this was to be expected. Finally, the vast majority of participants (77.2\%) had no previous VR experience.

$<<<$ Insert Table 1 here $>>>$ 


\section{Findings}

The data were analyzed following a two-step approach. First, we conducted confirmatory factor analysis (CFA) in order to test the appropriateness of the measurement model using SPSS. Second, we tested the structural model for hypothesis testing using MPlus 8.1 (Muthén \& Muthén, 2018). Table 2 provides an overview of the CFA. The results show that all factor loadings are above 0.7. In addition, all AVE scores are above the cut-off point of 0.5 (Hair et al., 2011). All composite reliability (CR) scores are above the cut-off point of 0.7 furthermore confirming validity of the measurement model. Further, Cronbach alpha score are all above 0.7 , which indicates reliability. In addition, Table 3 displays the inter-construct correlations which are all below the square roots of AVE of each construct. This indieates discriminant validity. Having established the measurement model, we conducted structural equation modelling (SEM) using the maximum likelihood estimator (Muthén \& Muthén, 2018). With regards to model fit indices, all measures were above the recommended threshold $\left(\chi^{2} 753.468, \mathrm{df}=360, \mathrm{p}<0.001 ; \mathrm{CFI}=0.951\right.$; $\mathrm{TLI}=0.945 ; \mathrm{RMSEA}=0.049 ; \mathrm{SRMR}=0.060)$.

\section{$<<<$ Insert Table 2 here $>>>$}

To test the hypothesised effects, structural relationships were modelled and tested in MPlus using a maximum likelihood estimator with robust error terms. The final model is shown in Figure 3. The majority of hypotheses were supported at $\mathrm{p}<.001$ except for H4a which was supported at $p<.003$. H1d and H1f had to be rejected, hence perceived ease of use did not influence emotional involvement and immersion.

Perceived ease of use was shown to be positively related to perceived usefulness $(\beta=.646$; $\left.\mathrm{p}<.001 ; \mathrm{R}^{2}=.320\right)$. Perceived ease of use $(\beta=.298 ; \mathrm{p}<.001)$ and perceived usefulness $(\beta=.451 ;$ 
$\mathrm{p}<.001$ ) have a positive effect on enjoyment explaining 37 percent of the variance. Perceived usefulness $(\beta=.493 ; p<.001)$ and enjoyment $(\beta=.321 ; p<.001)$, both influence emotional involvement, explaining 42.5 percent of the variance. In addition, perceived usefulness influences immersion $\left(\beta=.593 ; \mathrm{p}<.001 ; \mathrm{R}^{2}=.280\right)$. Enjoyment $(\beta=.412 ; \mathrm{p}<.001)$, immersion $(\beta=.166 ; p<.003)$ and emotional involvement $(\beta=.340 ; p<.001)$ influence positive emotions, explaining 54 percent of the variance. Furthermore, enjoyment $(\beta=.390 ; p<.001)$, emotional involvement $(\beta=.297 ; \mathrm{p}<.001)$ and immersion $(\beta=.291 ; \mathrm{p}<.001)$ influence flow, explaining 65 percent of the variance. Finally, perceived usefulness $(\beta=.255 ; p<.001)$, positive emotions $(\beta=.225 ; \mathrm{p}<.001)$ and flow $(\beta=.322 ; \mathrm{p}<.001)$ have a positive influence on behavioural intentions and explain 37 percent of the variance.

\section{$<<$ Insert Figure 3 here $>>>$}

Overall, results show that perceived usefulness is influenced by perceived ease of use and positively related to enjoyment, emotional involvement, immersion and behavioural intentions. Enjoyment, as a mediating variable, was found to positively influence emotional involvement, positive emotions and flow. In addition, emotional involvement forms a mediating effect in the hypothesised model and positively influences positive emotions and flow. Immersion was found to positively influence positive emotions at a slightly weaker level than its influence on flow. Finally, H5 and H6 were supported as both positive emotions and flow have a positive influence on behavioural intentions.

\section{$<<<$ Insert Table 4 here $>>>$}

\section{Discussion and Conclusion}

This study aimed to explore the antecedents of the behavioral intention to use VR within the science festival context. In particularly, this study took usability and gratifications as a 
theoretical foundation, merging the two theories in order to obtain usability and affective needs factors on VR adoption. Looking at gratification factors that influence people's behavioral intention to learn and engage with science, VR was found to be an engaging technology and if designed appropriately (easy to use and useful), people tended to have enjoyable, immersive and emotional experiences that influenced their overall state of flow and positive emotions hence, positively influenced their behavioral intention to be more engaged in the future. This is in line with previous research that confirmed that users receive interactive experience, a rich amount of information and a feeling of presence when using VR (Tussyadiah et al., 2018). The UG\&T proposed that needs have to be satisfied in order to lead to positive expectations which was confirmed by this study. According to Rauschnabel et al. (2017), the UG\&T is a flexible theory that invites the inclusion of additional theoretical perspectives and this study proposed and confirmed a theoretical framework including usability factors that explain the behavioral intentions to engage with science after experiencing an immersive, emotional and entertaining VR application.

The importance of incorporating usability factors as part of VR gratification research is particularly important as proper VR application design and implementation has important implications on the overall hedonic value of the application. For example, previous studies found that application design and user interface influence hedonic application attributes and ultimately satisfaction and behavioral intentions (Han et al., 2018). Therefore, PU and PEU can be considered one of the first and important steps of ensuring that VR applications lead to hedonic experiences. Factors such as immersion and flow have been well tested in the gaming context, where users utilize VR in order to escape the reality, becoming one with the experience while satisfying their curiosity. This was to some extent confirmed by Pallavicini et al. (2017) who 
found that VR experiences evoke more anxiety but are more appealing than 2D gaming.

Therefore, this study supports previous research by confirming that highly and immersive VR experiences lead to positive behavioral intentions. However, one has to keep in mind that events and festivals are activities that are often attended in order to escape daily life, make new memories and personally communicate with performers and other festival goers (van Winkle et al., 2019). Consequently, it is immensely important whenever discussing the use of new technologies for the enhancement of experiences that festival goers' benefits and gains are kept in consideration. A co-creation of value, whereby festival goers are part of the design and consumption process is inevitable in order to ensure that value is created (Minkiewicz et al., 2014). One solution to this problem was previously suggested by Rauschnabel et al. (2019) who revealed that inspiration will play an increasingly important role when designing immersive applications. Within the event and festival context, the use of mixed reality devices, such as Hololens, could overcome some of the barriers of $V \mathrm{R}$ such as isolation and limited interaction, while still providing festival goers with enhanced experiences.

\section{Theoretical Implications}

Theoretically, this study extended our understanding of the role of VR as part of the science festival experience. This study has shown that the integration of TAM and U\&GT creates an understanding of how VR applications can be used in order to engage the general public with science. The unique contribution of this study lies in the identification of five gratification factors that influence the behavioral intentions to use VR in the festival context. In particular, limited research has looked at the connections of emotional involvement, positive emotions and flow which can be considered one of the key contributions. We believe that this, coupled with the inclusion of usability within the VR context, creates a novel approach to 
studying festival goers' intention to continuously learn about science festivals and visit festival locations in the future. This is particularly important considering that science festivals often only reach the already converted thus, neglect to provide access to new knowledge to new audiences (Bultitude, 2014). Through the use of easy to use, useful, emotional engaging, immersive and enjoyable VR applications, the general public reaches a state of flow and positive emotions which helps to create an overall interest in science. Considering the overall strategy of engaging adults in lifelong learning (Corrales-Herrero \& Rodriguez-Prado, 2018), this is an important role that VR can play, not only as part of festivals but in order to deliver knowledge across all areas of daily life.

For instance, first attempts have been made for medicaleducation of patients (Moorhouse et al., 2019a) or as part of class room activities (Cuendet et al., 2013). In addition, looking at the bigger picture and assuming that these findings are transferable to other subjects or areas of everyday life, VR has the potential to aidin the dissemination of knowledge and facts as well as engage the general public with things that they might not otherwise engage with. Applications for this could range from education about social problems in increasingly urbanised environments, to political engagement of young traditionally non engaging voters.

\section{Practical Implications}

This study identified a number of practical implications. First, usability influenced gratifications of VR applications at science festivals and in particular, perceived usefulness is the most important usability indicator. Thus, festival organizers and application designers have to focus on content design as appropriate and useful VR content is considered a key in order to create pleasurable VR experiences which ultimately influence users' decision to engage with festival content and sites. Second, science festival participants found that well-designed and 
pleasurable VR experiences influence their engagement with science heritage hence, immersive technologies should be considered as a stepping stone for science festival organizers to engage new audiences in order to facilitate life-long learning through immersive and enjoyable public engagement activities. It is anticipated that VR technologies can aid to create attractive science experience for non-engaged audiences. This study found that VR is a tool to create positive emotions, engaging experiences and an overall sense of flow and this is expected to promote the causes of festivals in the future, attract new markets and enhance the overall festival experience while promoting a sense of learning. Further, VR could add to sponsorship opportunities through VR content for the financial success of festivals and events. One has to consider that the design of powerful and effective VR applications is costly and thus, considering the only temporary nature of events and festivals, managers need to consider how VR applications can be designed in order to be reusable for different events and festivals. For instance, in the case of the science festival, content could be made available to city councils in order to continue to promote science heritage to visitors and residents in the future. The involvement of multiple stakeholders in application design and implementation is therefore considered a viable way in order to co-create value and ensure long term success of VR applications. Finally, previous research explored the link between fashionability of VR glasses and the behavioral intentions. Herz and Rauschnabel's study (2019) was conducted in a generic business and marketing context however, for special events (e.g. fashion shows, launching events), this is another consideration for managers and practitioners.

\section{Limitations and Future Research}

There are a number of limitations which need to be addressed. First, data were collected for a specific VR application for the science festival in Manchester hence, this limits 
generalisations and further research with different applications should be conducted in order to generalise findings. In addition, the present study used the theoretical concept of usability and gratifications for model development. Additional factors such as anxiety (Pallavicini et al., 2017) or perceived risks should be explored using a mixed methods approach in order to enhance the explanatory power of the model. Another limitation is that this study focused on direct effects among constructs however, future research could incorporate mediating effects of gratification between usability and consequences. Finally, the present sample had only limited previous knowledge of VR and therefore, we could not explore differences between those participants with or without VR knowledge. With VR becoming more and more part of people's lives, future research should take previous experience into account when analysing VR experiences as the novelty factor might contribute to a positive or negative experience as shown in previous research. For event organizers this would be an important finding for the implementation of VR applications and acceptance among different types of visitors. There are however also risk factors that should be kept in mind. One aspect is the fact that so far VR experiences are solitudinous even if embedded in otherwise social settings due to the requirement of head mounted displays. Also, a topic that so far has received little attention is that of privacy concerns (Herz \& Rauschnabel, 2019). What is user's attitude to VR privacy given that these experiences are increasingly personalised to target users' specific interests. Therefore, future research should consider risks vs. rewards from a user privacy perspective in regard to user VR adoption in the event context. 


\section{Appendix}

Measurement items

\section{Perceived Ease of Use (Huang et al., 2013; Jung et al., 2018)}

Learning to use VR was easy for me

I didn't find it difficult to get the VR application to do what I wanted it to do

I found the VR application flexible to interact with

It was easy for me to become skillful at using the VR application

\section{Perceived Usefulness (Huang et al., 2013; Jung et al., 2018)}

Using the VR application enhances the effectiveness of Manchester Science

Heritage tour planning

Using the VR application increases my productivity in Manchester Science

Heritage tour planning

VR is useful for Manchester Science Heritage tour planning

Using the VR application enabled me to explore Manchester Science

Heritage tour information more conveniently

Enjoyment (Huang et al., 2013; Jung et al., 2018)

I enjoyed experiencing the virtual world in the VR application very much

I thought experiencing VR was quite enjoyable

I would describe the experience of the VR application as very interesting

The VR experience was fun

\section{Positive Emotions (Huang et al., 2013)}

I felt the following emotions... 
Joy

Cheerfulness

Delight

\section{Emotional Involvement (Huang et al., 2013)}

I felt carried away by the VR experience

I felt as if I am part of the VR experience

I felt deeply about the VR experience

Flow (Huang et al., 2013)

When experiencing the VR application, my attention was totally focused

Experiencing the VR application excited my curiosity

Experiencing the VR application was intrinsically interesting

\section{Immersion (Hamari et al., 2016)}

I was completely immersed in the VR application

I lost track of time while playing the VR application.

I became very involved in the VR application forgetting about other things

\section{Behavioral Intention (Huang et al., 2013)}

I wanted to find out more information about Manchester Science Heritage

I gained an interest in visiting Manchester Science Heritage in person

I want to try to visit Manchester Science Heritage Sites in the future

I am willing to recommend Manchester Science Heritage to others 


\section{References}

Atkins, N. (2017). How The Coachella Music Festival embraced virtual reality. Upload VR. https://uploadvr.com/coachella-embraced-virtual-reality/

Bachen, C. M., Hernández-Ramos, P., Raphael, C., \& Waldron, A. (2016). How do presence, flow, and character identification affect players' empathy and interest in learning from a serious computer game?. Computers in Human Behavior, 64, 77-87. https://doi.org/10.1016/j.chb.2016.06.043

Bultitude, K. (2014). Science festivals: Do they succeed in reaching beyond the 'already engaged'. Journal of Science Communication, 13(4), 1-3. https://doi.org/10.22323/2.13040301

Campos, J. J., Frankel, C. B., \& Camras, L. (2004). On the nature of emotion regulation. Child Development, 75(2), 377-394. https://doi.org/10.1111/j.1467-8624.2004.00681.x

Chen, G. M. (2011). Tweet this: A uses and gratifications perspective on how active Twitter use gratifies a need to connect with others. Computers in Human Behavior, 27(2), 755-762. https://doi.org/10.1016/1.chb.2010.10.023

Chen, Y. M., Hsu, T. H., \& Lu, Y. J. (2018). Impact of flow on mobile shopping intention. Journal of Retailing and Consumer Services, 41, 281-287. https://doi.org/10.1016/j.jretconser.2017.04.004

Chong, A. Y. L., Chan, F. T., \& Ooi, K. B. (2012). Predicting consumer decisions to adopt mobile commerce: Cross country empirical examination between China and Malaysia. Decision Support Systems, 53, 34-43. https://doi.org/10.1016/j.dss.2011.12.001 
Corrales-Herrero, H., \& Rodríguez-Prado, B. (2018). The role of non-formal lifelong learning at different points in the business cycle. International Journal of Manpower, 39(2), 334352. https://doi.org/10.1108/IJM-08-2016-0164

Cuendet, S., Bonnard, Q., Do-Lenh, S., \& Dillenbourg, P. (2013). Designing augmented reality for the classroom. Computers \& Education, 68, 557-569. https://doi.org/10.1016/j.compedu.2013.02.015

Davis, F. D., Bagozzi, R. P., \& Warshaw, P. R. (1989). User acceptance of computer technology: a comparison of two theoretical models. Management Science, 35(8), 982-1003. https://doi.org/10.1287/mnsc.35.8.982

Easson, H., \& Leask, A. (2019). After-hours events at the NationalMuseum of Scotland: A product for attracting, engaging and retaining new museum audiences?. Current Issues in Tourism, 23(11), 1343-1356. https://doi.org/10,1080/13683500.2019.1625875

Fredrickson, B. L. (1998). What good are positive emotions?. Review of General Psychology, 2(3), 300-319. https://doi.org/10.1037/1089-2680.2.3.300

Hair, J. F., Ringle, C. M., \& Sarstedt, M. (2011). PLS-SEM: Indeed a silver bullet. Journal of Marketing theory and Practice, 19(2), 139-152. https://doi.org/10.2753/MTP1069$\underline{6679190202}$

Hamari, J., Shernoff, D. J., Rowe, E., Coller, B., Asbell-Clarke, J., \& Edwards, T. (2016). Challenging games help students learn: An empirical study on engagement, flow and immersion in game-based learning. Computers in Human Behavior, 54, 170-179. https://doi.org/10.1016/j.chb.2015.07.045 
Han, D. I. \& tom Dieck, M.C. (2019). Calling for user-centric VR design research in hospitality and tourism. Hospitality \& Society, 9(2), 237-246. https://doi.org/10.1386/hosp.9.2.237 7

Han, D. I., tom Dieck, M. C., \& Jung, T. (2018). User experience model for augmented reality applications in urban heritage tourism. Journal of Heritage Tourism, 13(1), 46-61. https://doi.org/10.1080/1743873X.2016.1251931

Hayashi, A., Chen, C., Ryan, T., \& Wu, J. (2004). The role of social presence and moderating role of computer self efficacy in predicting the continuance usage of e-learning systems. Journal of Information Systems Education 15(2), 139-54. https://jise.org/Volume15/n2/JISEv15n2p139.pdf

Hernik, J., \& Jaworska, E. (2018, March). The effect of enjoyment on learning. INTED2018 Proceedings (pp. 508-514). https://doi,org/10.21125/inted.2018.1087

Herz, M., \& Rauschnabel, P. A. (2019). Understanding the diffusion of virtual reality glasses: The role of media, fashion and technology. Technological Forecasting and Social Change, 138, 228-242. https://doi.org/10.1016/j.techfore.2018.09.008

Hodgson, P., Lee, V. W., Chan, J. C., Fong, A., Tang, C. S., Chan, L., \& Wong, C. (2019). Immersive virtual reality (IVR) in higher education: Development and implementation. In M. C. tom Dieck, \& T. Jung (Eds.). Augmented reality and virtual reality (pp. 161173). Springer.

Holsapple, C. W., \& Wu, J. (2007). User acceptance of virtual worlds: the Hedonic framework. ACM SIGMIS Database: The DATABASE for Advances in Information Systems, 38(4), 86-89. https://doi.org/10.1145/1314234.1314250 
Huang, Y. C., Backman, S. J., Backman, K. F., McGuire, F. A., \& Moore, D. (2018). An investigation of motivation and experience in virtual learning environments: A selfdetermination theory. Education and Information Technologies, 24(1), 591-611 (2019). https://doi.org/10.1007/s10639-018-9784-5

Huang, Y. C., Backman, S. J., Backman, K. F., \& Moore, D. (2013). Exploring user acceptance of 3D virtual worlds in travel and tourism marketing. Tourism Management, 36, 490501. https://doi.org/10.1016/j.tourman.2012.09.009

Jensen, E., \& Buckley, N. (2014). Why people attend science festivals: Interests, motivations and self-reported benefits of public engagement with research. Public Understanding of Science, 23(5), 557-573. https://doi.org/10.1177/09636625/12458624

Jung, T. H., \& tom Dieck, M. C. (2017). Augmented reality, virtual reality and 3D printing for the co-creation of value for the visitor experience at cultural heritage places. Journal of Place Management and Development, 10(2), 140-151. https://doi.org/10.1108/JPMD-07$\underline{2016-0045}$

Jung, T., tom Dieck, M. C., Rauschnabel, P., Ascenção, M., Tuominen, P., \& Moilanen, T. (2018). Functional, Hedonic or Social? Exploring Antecedents and Consequences of Virtual Reality Rollercoaster Usage. In T. Jung \& M.C. tom Dieck (Eds.), Augmented Reality and Virtual Reality (pp. 247-258). Springer.

Kim, D. Y., Park, J., \& Morrison, A. M. (2008a). A model of traveller acceptance of mobile technology. International Journal of Tourism Research, 10(5), 393-407. https://doi.org/10.1002/jtr.669 
Kim, H., Lee, D., \& Hwang, J. S. (2018). Dividing network externality into the number of peers and users: Focusing on sociability and enjoyment in online games. Information Technology \& People, 31(2), 388-404. https://doi.org/10.1108/ITP-04-2017-0129

Laver, K. E., George, S., Thomas, S., Deutsch, J. E., \& Crotty, M. (2015). Virtual reality for stroke rehabilitation. Cochrane Database of Systematic Reviews. https://doi.org/10.1002/14651858.CD008349.pub3

Lee, H., Jung, T. H., tom Dieck, M. C., \& Chung, N. (2020). Experiencing immersive virtual reality in museums. Information \& Management, 57(5), 103229. https://doi.org/10.1016/j.im.2019.103229

Minkiewicz, J., Evans, J., \& Bridson, K. (2014). How do consumers co-create their experiences? An exploration in the heritage sector. Journal of Marketing Management, 30(1-2), 3059. https://doi.org/10.1080/0267257X.2013.800899

Moorhouse, N., Jung, T., Shi, X., Amin, F., Newsham, J., \& McCall, S. (2019a). Pulmonary rehabilitation in virtual reality for COPD Patients. In M. C. tom Dieck, M. C., \& T. Jung (Eds.). The power of AR and VR for business (pp. 277-290), Springer.

Moorhouse, N., tom Dieck, M. C., \& Jung, T. (2019b). An experiential view to children learning in museums with Augmented Reality. Museum Management and Curatorship, 34(4), 402-418. https://doi.org/10.1080/09647775.2019.1578991

Muthén, L. K., \& Muthén, B. O. (2018). Mplus: Statistical analysis with latent variables (Version 8.1). Los Angeles: Muthén \& Muthén.

Mütterlein, J., \& Hess, T. (2017). Immersion, presence, interactivity: Towards a joint understanding of factors influencing virtual reality acceptance and use. AMCIS 2017. https://aisel.aisnet.org/amcis2017/adoptionit/presentations/17/ 
Nysveen, H., Pedersen, P. E., \& Thorbjørnsen, H. (2005). Intentions to use mobile services: Antecedents and cross-service comparisons. Journal of the Academy of Marketing Science, 33(3), 330-346. https://doi.org/10.1177/0092070305276149

Pallavicini, F., Ferrari, A., Zini, A., Garcea, G., Zanacchi, A., Barone, G., \& Mantovani, F. (2017). What distinguishes a traditional gaming experience from one in virtual reality? An exploratory study. In T. Ahram, \& C. Falcao (Eds.), Advances in human factors in wearable technologies and game design. Proceedings of the AHFE 2017 Conference on advances in intelligent systems and computing (pp. 225-231). Springer.

Pavlou, P. A. (2003). Consumer acceptance of electronic commerce: Integrating trust and risk with the technology acceptance model. Internationat Journal of Electronic Commerce, 7(3), 101-134. https://doi.org/10.1080/10864415.2003.11044275

Peilloux, A., \& Botella, M. (2016). Ecological and dynamical study of the creative process and affects of scientific students working ingroups. Creativity Research Journal, 28(2), 165170. https://doi.org/10.1080/10400419.2016.1162549

Rauschnabel, P. A. (2018). Virtually enhancing the real world with holograms: An exploration of expected gratifications of using augmented reality smart glasses. Psychology \& Marketing, 35(8), 557-572. https://doi.org/10.1002/mar.21106

Rauschnabel, P. A., Felix, R., \& Hinsch, C. (2019). Augmented reality marketing: How mobile AR-apps can improve brands through inspiration. Journal of Retailing and Consumer Services, 49, 43-53. https://doi.org/10.1016/j.jretconser.2019.03.004

Rauschnabel, P. A., Rossmann, A., \& tom Dieck, M.C. (2017). An adoption framework for mobile augmented reality games: The case of Pokémon Go. Computers in Human Behavior, 76, 276-286. https://doi.org/10.1016/j.chb.2017.07.030 
Raza, S. A., Umer, A., \& Shah, N. (2017). New determinants of ease of use and perceived usefulness for mobile banking adoption. International Journal of Electronic Customer Relationship Management, 11(1), 44-65. https://doi.org/10.1504/IJECRM.2017.086751

Rai A., Lang, S. S., \& Welker, R. B. (2002). Assessing the validity of IS success models. Information Systems Research, 13(1), 50-69. https://doi.org/10.1287/isre.13.1.50.96

Saadé, R., \& Bahli, B. (2005). The impact of cognitive absorption on perceived usefulness and perceived ease of use in on-line learning: an extension of the technology acceptance model. Information \& Management, 42(2), 317-327. https://doi.org/10.1016/j.im.2003.12.013

Särkelä, H., Takatalo, J., Komulainen, J., Nyman, G., \& Häkkinen, J. (2004). Attitudes to new technology and experiential dimensions of two different digital games. In R. Raisamo (ed.). Proceedings of the third Nordic conference on human-computer interaction (pp. 349-352). Association for Computing Machinery https://doi.org/10.1145/1028014.1028069

Shao, G. (2009). Understanding the appeal of user-generated media: a uses and gratification perspective. Internet Résearch, 19(1), 7-25. https://doi.org/10.1108/10662240910927795

Shaw, M. P. (1989). The eureka process: A structure for the creative experience in science and engineering. Creativity Research Journal, 2(4), 286-298. https://doi.org/10.1080/10400418909534325

Shin, D. (2017). How does immersion work in augmented reality games? A user-centric view of immersion and engagement. Information, Communication \& Society, 22(9) 1212-1229. https://doi.org/10.1080/1369118X.2017.1411519 
Shin, D. (2009). Towards an understanding of the consumer acceptance of mobile wallet. Computers in Human Behavior, 25(6), 1343-1354. https://doi.org/10.1016/j.chb.2009.06.001

Shin, D., \& Biocca, F. (2017). Health experience model of personal informatics: The case of a quantified self. Computers in Human Behavior, 69, 62-74. https://doi.org/10.1016/j.chb.2016.12.019

Shin, D. H. (2011). Understanding e-book users: Uses and gratification expectancy model. New Media \& Society, 13(2), 260-278. https://doi.org/10.1177/1461444810372163

Teo, T., \& Noyes, J. (2011). An assessment of the influence of perceived enjoyment and attitude on the intention to use technology among pre-service teachers: A structural equation modeling approach. Computers \& Education, 57(2), 1645-1653. https://doi.org/10.1016/j.compedu.2011.03.002

tom Dieck, M. C., Jung, T. H., Kim, W. G., \& Moon, Y. (2017). Hotel guests' social media acceptance in luxury hotels. International Journal of Contemporary Hospitality Management, 29(1), 530-550.https://doi.org/10.1108/IJCHM-10-2015-0552

tom Dieck, D., tom Dieck, M. C., Jung, T., \& Moorhouse, N. (2018a). Tourists' virtual reality adoption: An exploratory study from Lake District National Park. Leisure Studies, 37(4), 371-383. https://doi.org/10.1080/02614367.2018.1466905

tom Dieck, M. C., Jung, T. H., \& Rauschnabel, P. A. (2018b). Determining visitor engagement through augmented reality at science festivals: An experience economy perspective. Computers in Human Behavior, 82, 44-53. https://doi.org/10.1016/j.chb.2017.12.043

Tredinnick, L. (2018). Virtual realities in the business world. Business Information Review, 35(1), 39-42. https://doi.org/10.1177/0266382118762257 
Tussyadiah, I. P., Wang, D., Jung, T. H., \& tom Dieck, M. C. (2018). Virtual reality, presence, and attitude change: Empirical evidence from tourism. Tourism Management, 66, 140154. https://doi.org/10.1016/j.tourman.2017.12.003

van Winkle, C. M., Bueddefeld, J. N., Halpenny, E. A., \& MacKay, K. J. (2019). The unified theory of acceptance and use of technology 2: Understanding mobile device use at festivals. Leisure Studies, 38(4), 634-650. https://doi.org/10.1080/02614367.2019.1618895

van Winkle, C., Cairns, A., J. MacKay, K., \& A. Halpenny, E. (2016).Mobile device use at festivals: opportunities for value creation. International Journal of Event and Festival Management, 7(3), 201-218. https://doi.org/10.1108/IJEFM-04-2016-0025

van Winkle, C., MacKay, K., \& Halpenny, E. (2018). Information and Communication technology and the festival experience. In J. Mair (Ed), The Routledge handbook of festivals (pp. 254-262). Routledge.

https://www.routledgehandbooks.com/doi/10.4324/9781315186320-26

Venkatesh, V. (2000). Determinants of perceived ease of use: integrating control, intrinsic motivation, and emotion into the technology acceptance model. Information Systems Research, 11(4), 342-365. https://doi.org/10.1287/isre.11.4.342.11872

Waugh, C. E., \& Fredrickson, B. L. (2006). Nice to know you: Positive emotions, self-other overlap, and complex understanding in the formation of a new relationship. The Journal of Positive Psychology, 1(2), 93-106. https://doi.org/10.1080/17439760500510569

Witmer, B. G., \& Singer, M. J. (1998). Measuring presence in virtual environments: A presence questionnaire. Presence: Teleoperators and Virtual Environments, 7(3), 225-240. https://doi.org/10.1162/105474698565686 
Wu, J., \& Lu, X. (2013). Effects of extrinsic and intrinsic motivators on using utilitarian, hedonic, and dual-purposed information systems: A meta-analysis. Journal of the Association for Information Systems, 14(3), 153-191. https://doi.org/10.17705/1jais.00325

Wu, J. H., \& Wang, S. C. (2005). What drives mobile commerce?: An empirical evaluation of the revised technology acceptance model. Information \& Management, 42(5), 719-729. https://doi.org/10.1016/j.im.2004.07.001

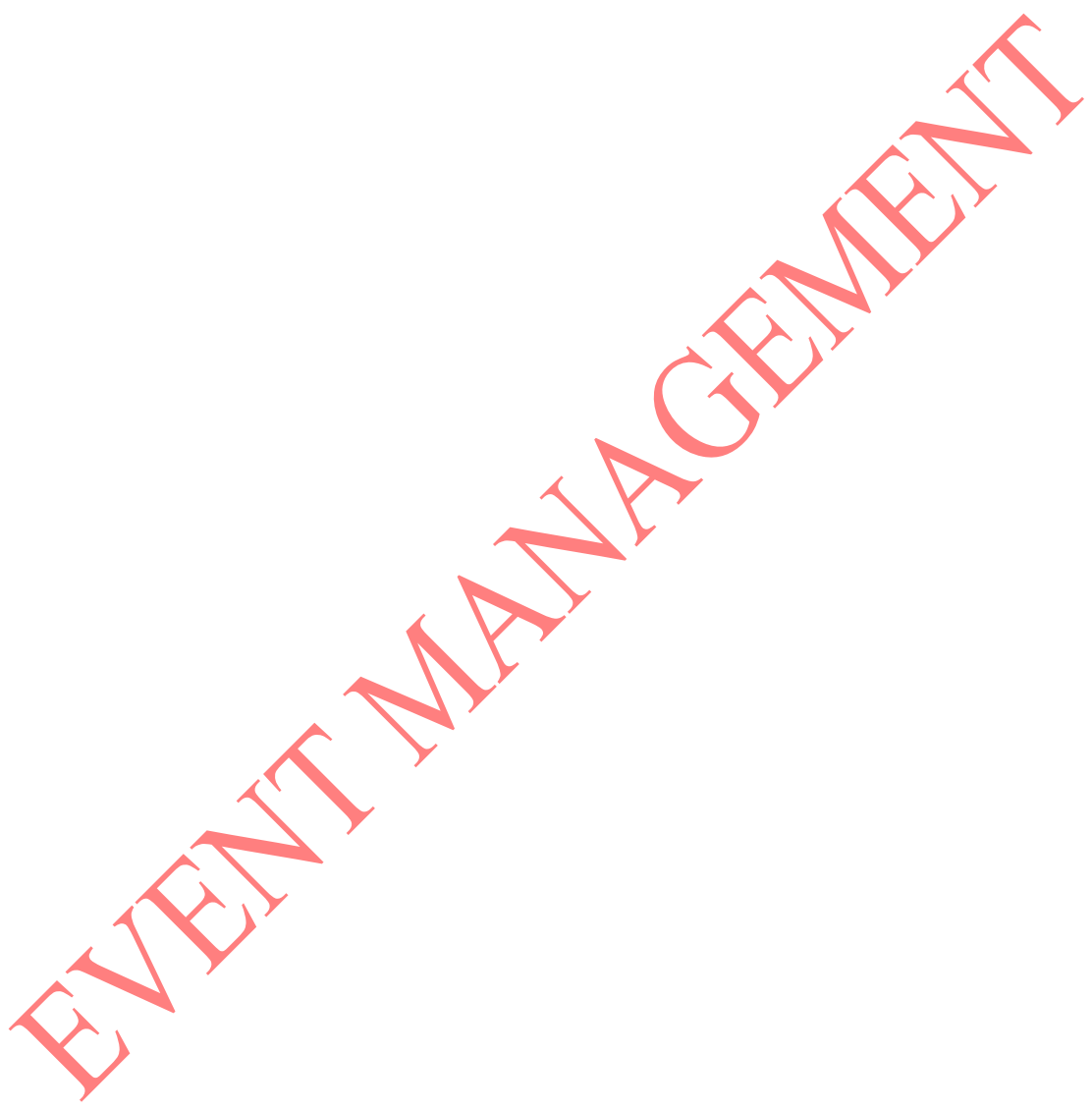




\section{Table 1}

Participants Profile

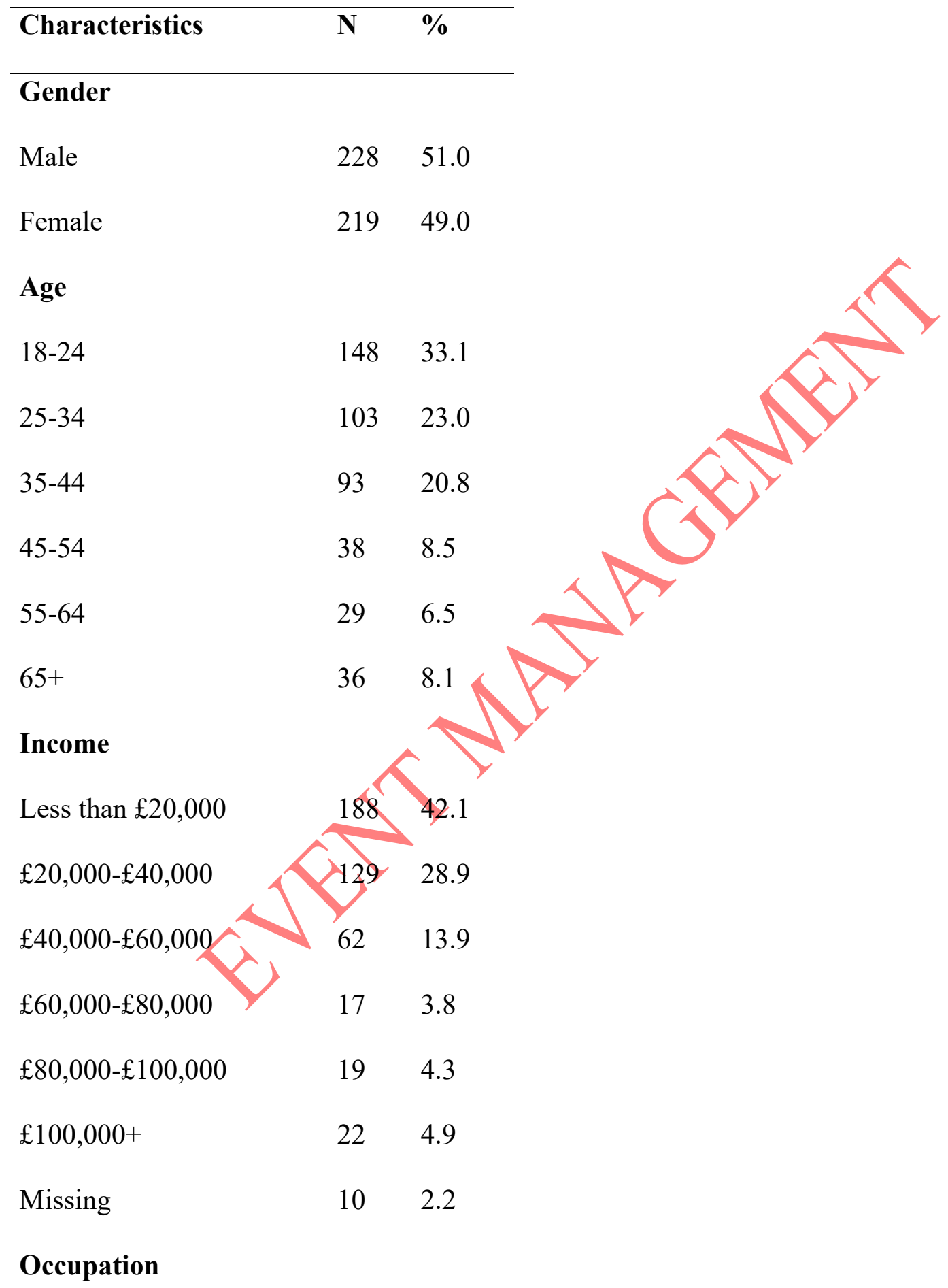

Full-time employed $\quad 187 \quad 41.8$ 


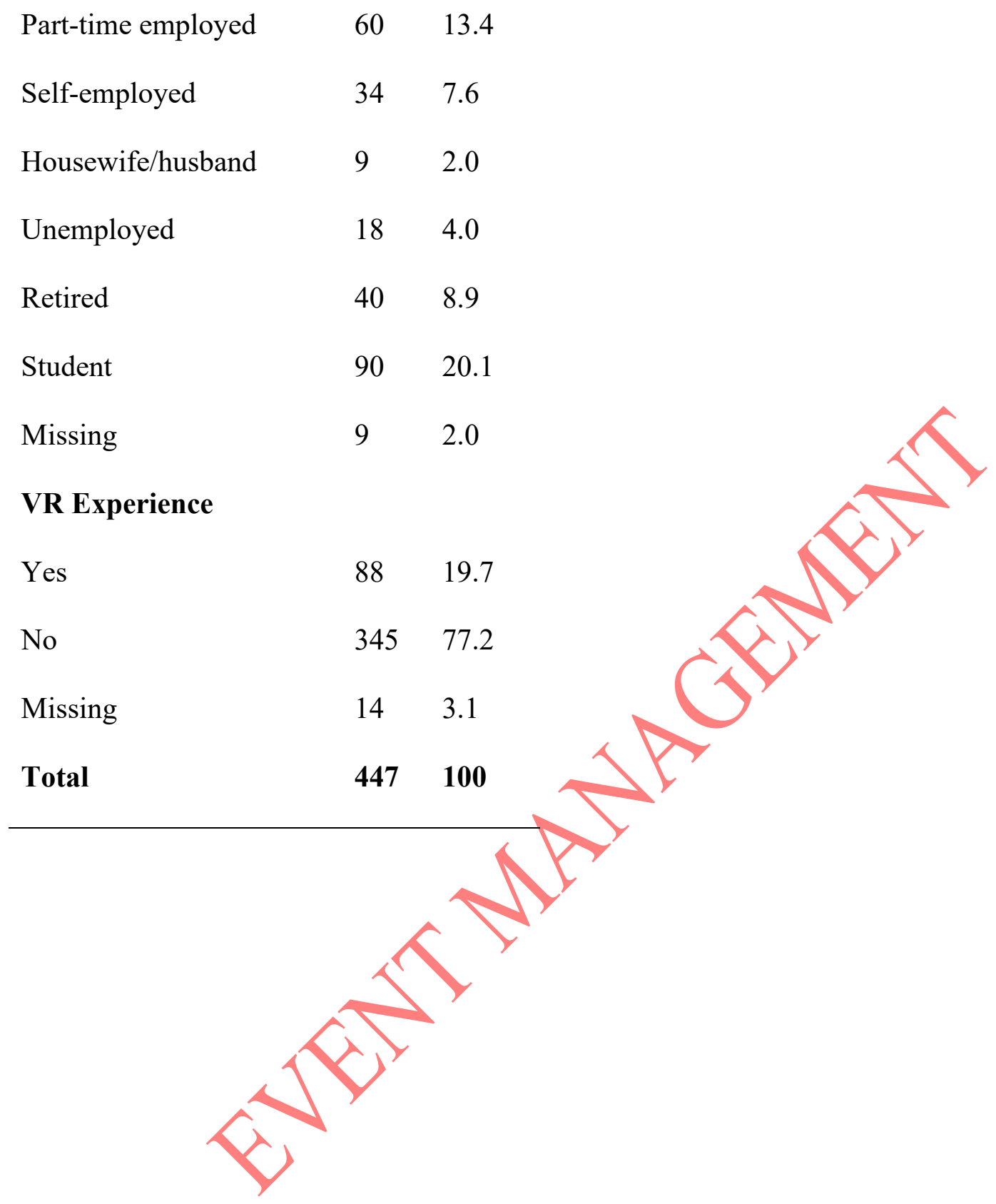




\section{Table 2}

Factor Loadings, Average Variance Extracted (AVE) and Composite Reliability (CR)

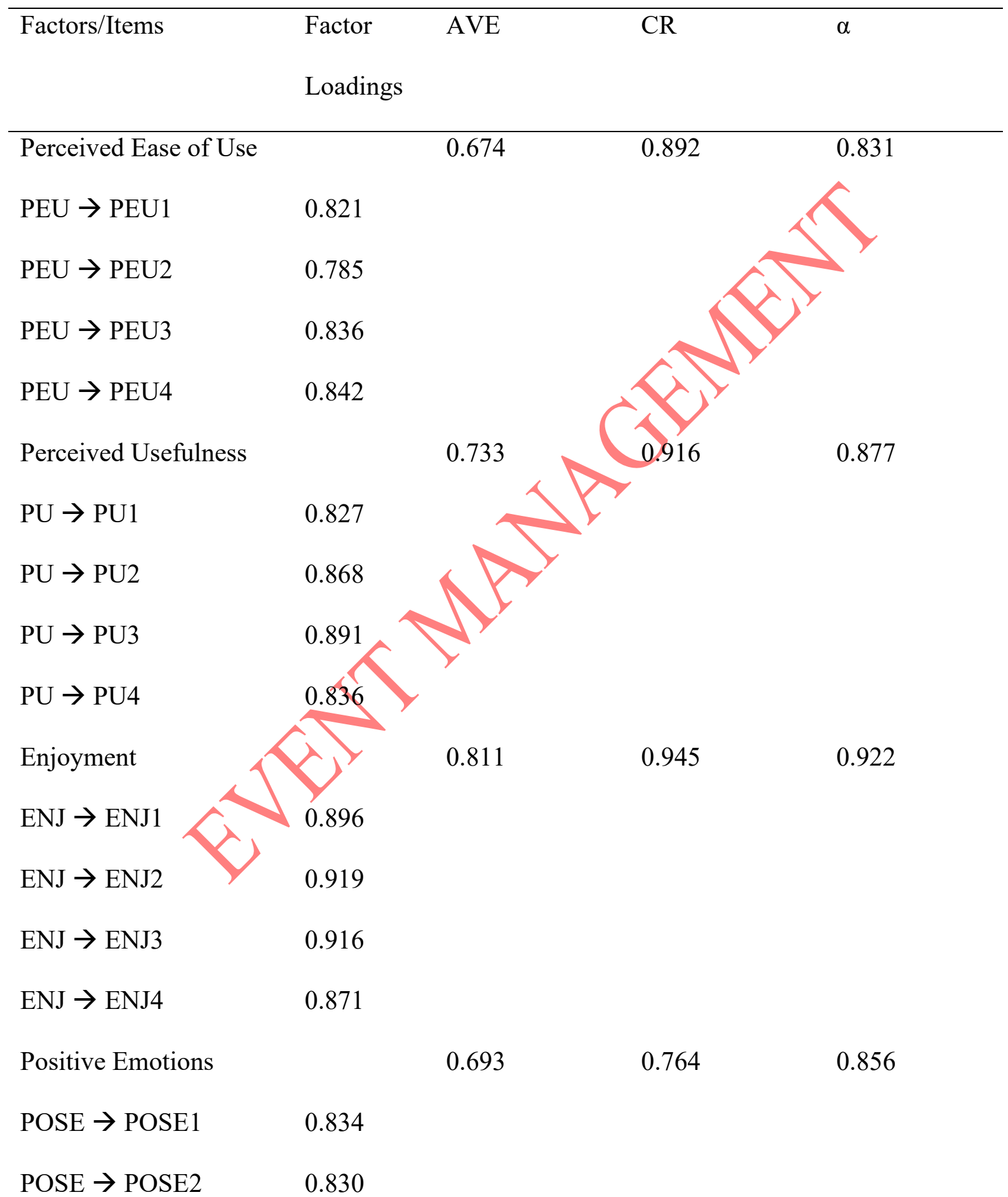




\begin{tabular}{|c|c|c|c|}
\hline POSE $\rightarrow$ POSE3 & 0.833 & & \\
\hline Emotional Involvement & 0.753 & 0.796 & 0.835 \\
\hline $\mathrm{EI} \rightarrow \mathrm{EI} 1$ & 0.858 & & \\
\hline $\mathrm{EI} \rightarrow \mathrm{EI} 2$ & 0.877 & & \\
\hline $\mathrm{EI} \rightarrow \mathrm{EI} 3$ & 0.869 & & \\
\hline Flow & 0.740 & 0.789 & 0.834 \\
\hline $\mathrm{FL} \rightarrow \mathrm{FL} 1$ & 0.821 & & \\
\hline $\mathrm{FL} \rightarrow \mathrm{FL} 2$ & 0.883 & & \\
\hline $\mathrm{FL} \rightarrow \mathrm{FL} 3$ & 0.875 & & \\
\hline Immersion & 0.699 & & 0.782 \\
\hline $\mathrm{IM} \rightarrow \mathrm{IM} 1$ & 0.816 & & \\
\hline $\mathrm{IM} \rightarrow \mathrm{IM} 2$ & 0.826 & & \\
\hline $\mathrm{IM} \rightarrow \mathrm{IM} 3$ & 0.865 & & \\
\hline Behavioral Intention & A & 0.932 & 0.901 \\
\hline $\mathrm{BI} \rightarrow \mathrm{BI} 1$ & & & \\
\hline $\mathrm{BI} \rightarrow \mathrm{BI} 2$ & & & \\
\hline $\mathrm{BI} \rightarrow \mathrm{BI} 3$ & 0.913 & & \\
\hline $\mathrm{BI} \rightarrow \mathrm{BI} 4$ & 0.857 & & \\
\hline
\end{tabular}




\section{Table 3}

Inter-construct correlations and square roots of AVE

\begin{tabular}{lllllllll}
\hline & PEU & PU & ENJ & POSE & EI & FL & IM & BI \\
\hline PEU & $\mathbf{0 . 8 2 1}$ & & & & & & \\
PU & 0.567 & $\mathbf{0 . 8 5 6}$ & & & & & & \\
ENJ & 0.490 & 0.555 & $\mathbf{0 . 9 0 0}$ & & & & & \\
POSE & 0.296 & 0.523 & 0.634 & $\mathbf{0 . 8 3 2}$ & & & & \\
EI & 0.247 & 0.432 & 0.542 & 0.559 & $\mathbf{0 . 8 6 8}$ & & \\
FL & 0.346 & 0.443 & 0.679 & 0.516 & 0.647 & $\mathbf{0 . 8 6 0}$ & & \\
IM & 0.270 & 0.472 & 0.432 & 0.482 & 0.663 & 0.631 & $\mathbf{0 . 8 3 6}$ & \\
BI & 0.123 & 0.351 & 0.408 & 0.369 & 0.231 & 0.348 & 0.330 & $\mathbf{0 . 8 8 0}$ \\
\hline
\end{tabular}

Note: The bold elements are the square roots of AVE; the remaining elements are cross-correlations between factors. 


\section{Table 4}

Hypotheses testing

\begin{tabular}{|c|c|c|c|c|}
\hline Hypotheses & Path & Estimates & p-Value & H Support \\
\hline H1a & $\mathrm{PEU} \rightarrow \mathrm{PU}$ & 0.646 & .001 & Accept \\
\hline $\mathrm{H} 1 \mathrm{~b}$ & $\mathrm{PEU} \rightarrow \mathrm{ENJ}$ & 0.298 & .001 & Accept \\
\hline H1c & $\mathrm{PU} \rightarrow \mathrm{ENJ}$ & 0.451 & .001 & Accept \\
\hline H1d & $\mathrm{PEU} \rightarrow \mathrm{EI}$ & -0.039 & .637 & Reject \\
\hline H1e & $\mathrm{PU} \rightarrow \mathrm{EI}$ & 0.447 & .001 & \\
\hline H1f & $\mathrm{PEU} \rightarrow \mathrm{IM}$ & -0.017 & .846 & \\
\hline $\mathrm{H} 1 \mathrm{~g}$ & $\mathrm{PU} \rightarrow \mathrm{IM}$ & 0.593 & & \\
\hline $\mathrm{H} 1 \mathrm{~h}$ & $\mathrm{PU} \rightarrow \mathrm{BI}$ & 0.255 & & Accept \\
\hline $\mathrm{H} 2 \mathrm{a}$ & $\mathrm{ENJ} \rightarrow \mathrm{EI}$ & 0.321 & .001 & Accept \\
\hline $\mathrm{H} 2 \mathrm{~b}$ & $\mathrm{ENJ} \rightarrow \mathrm{POSE}$ & & .001 & Accept \\
\hline $\mathrm{H} 2 \mathrm{c}$ & ENJ & & .001 & Accept \\
\hline $\mathrm{H} 3 \mathrm{a}$ & & 0.340 & .001 & Accept \\
\hline $\mathrm{H} 3 \mathrm{~b}$ & & 0.297 & .001 & Accept \\
\hline $\mathrm{H} 4 \mathrm{a}$ & & 0.166 & .003 & Accept \\
\hline $\mathrm{H} 4 \mathrm{~b}$ & $\mathrm{IM} \rightarrow \mathrm{FL}$ & 0.291 & .001 & Accept \\
\hline H5 & $\mathrm{POSE} \rightarrow \mathrm{BI}$ & 0.225 & .001 & Accept \\
\hline H6 & $\mathrm{FL} \rightarrow \mathrm{BI}$ & 0.322 & .001 & Accept \\
\hline
\end{tabular}


Figure 1

Proposed Model

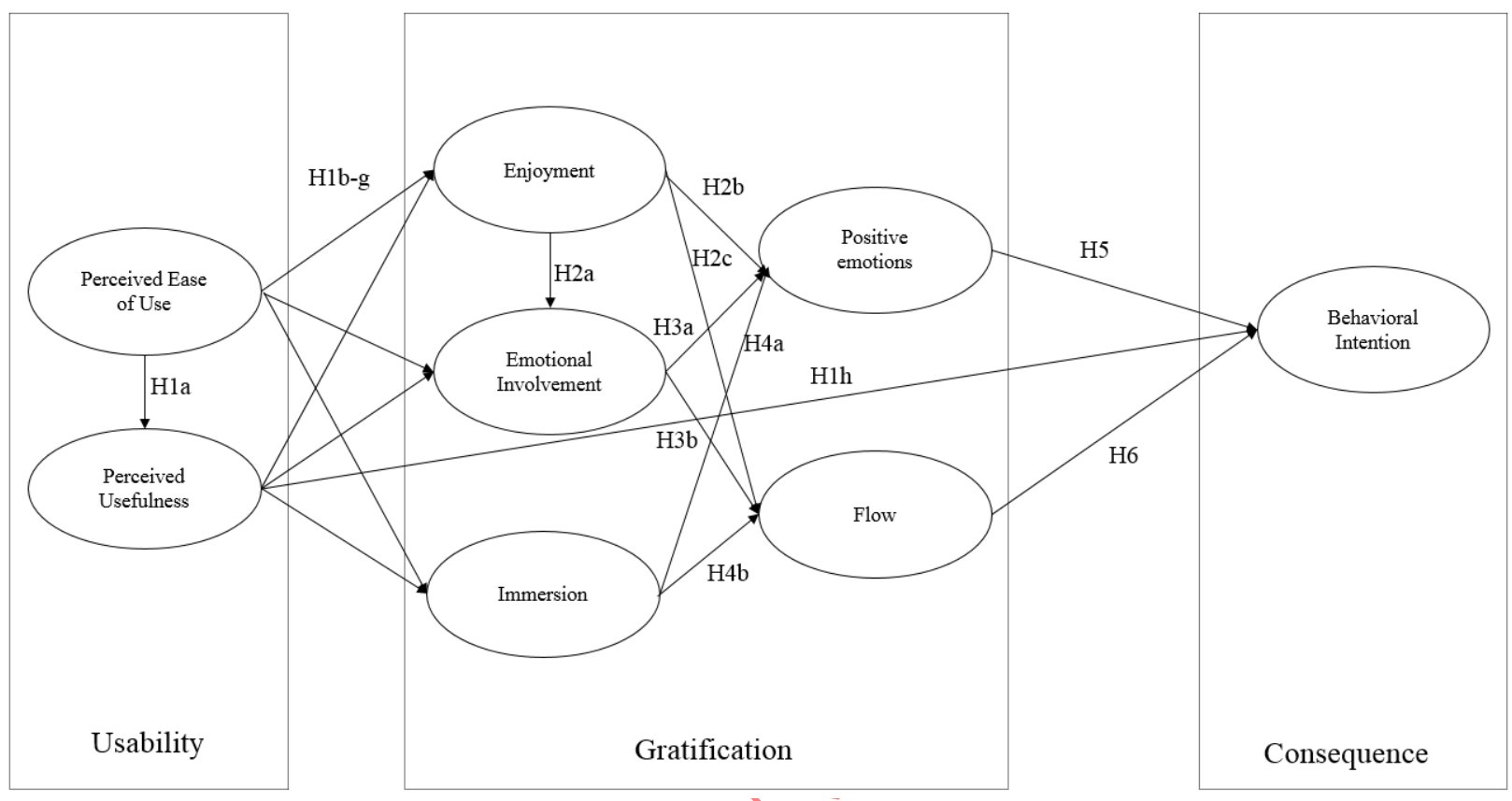




\section{Figure 2}

\section{Pop-up VR Experience}

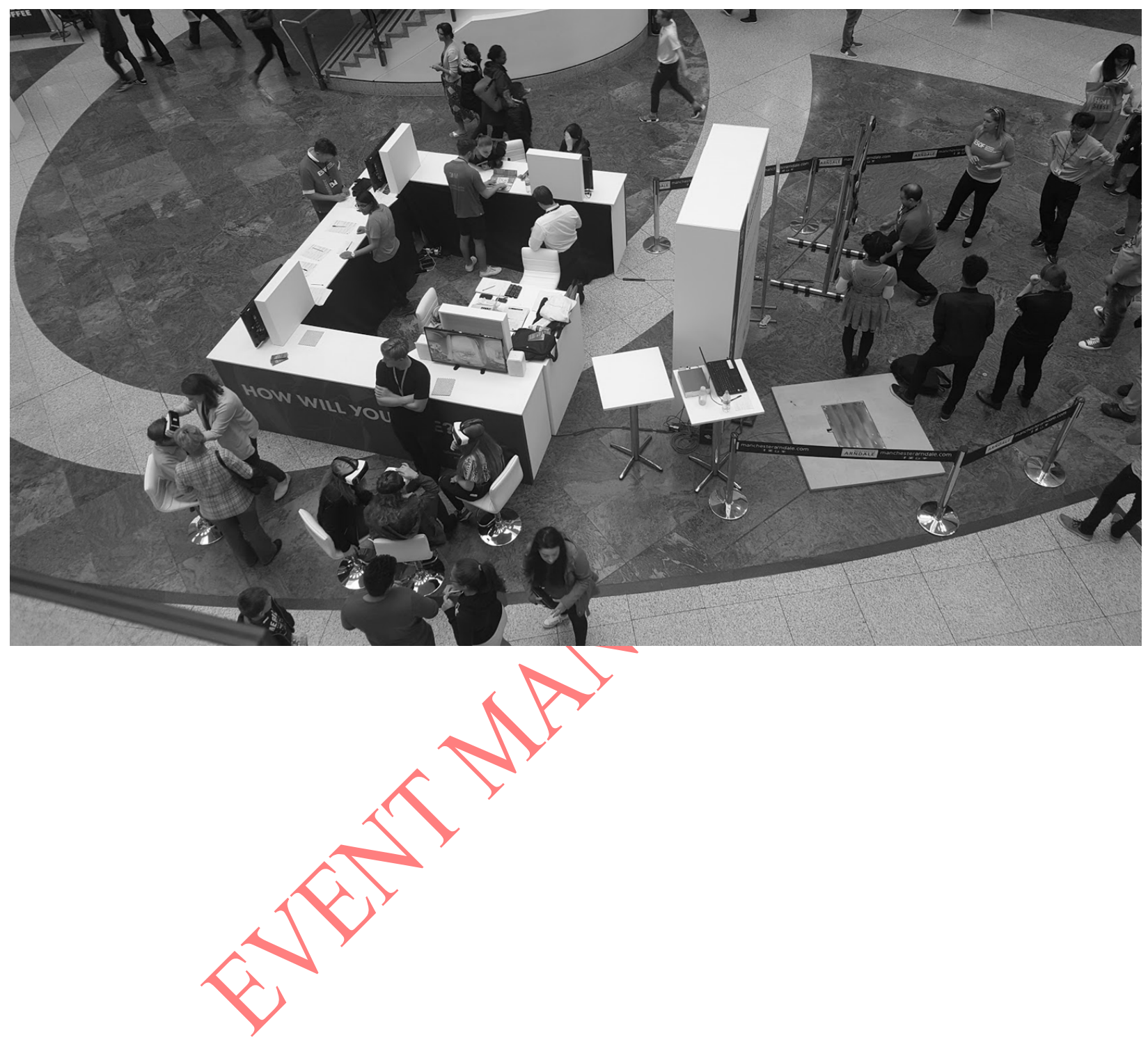


Figure 3

Final Model

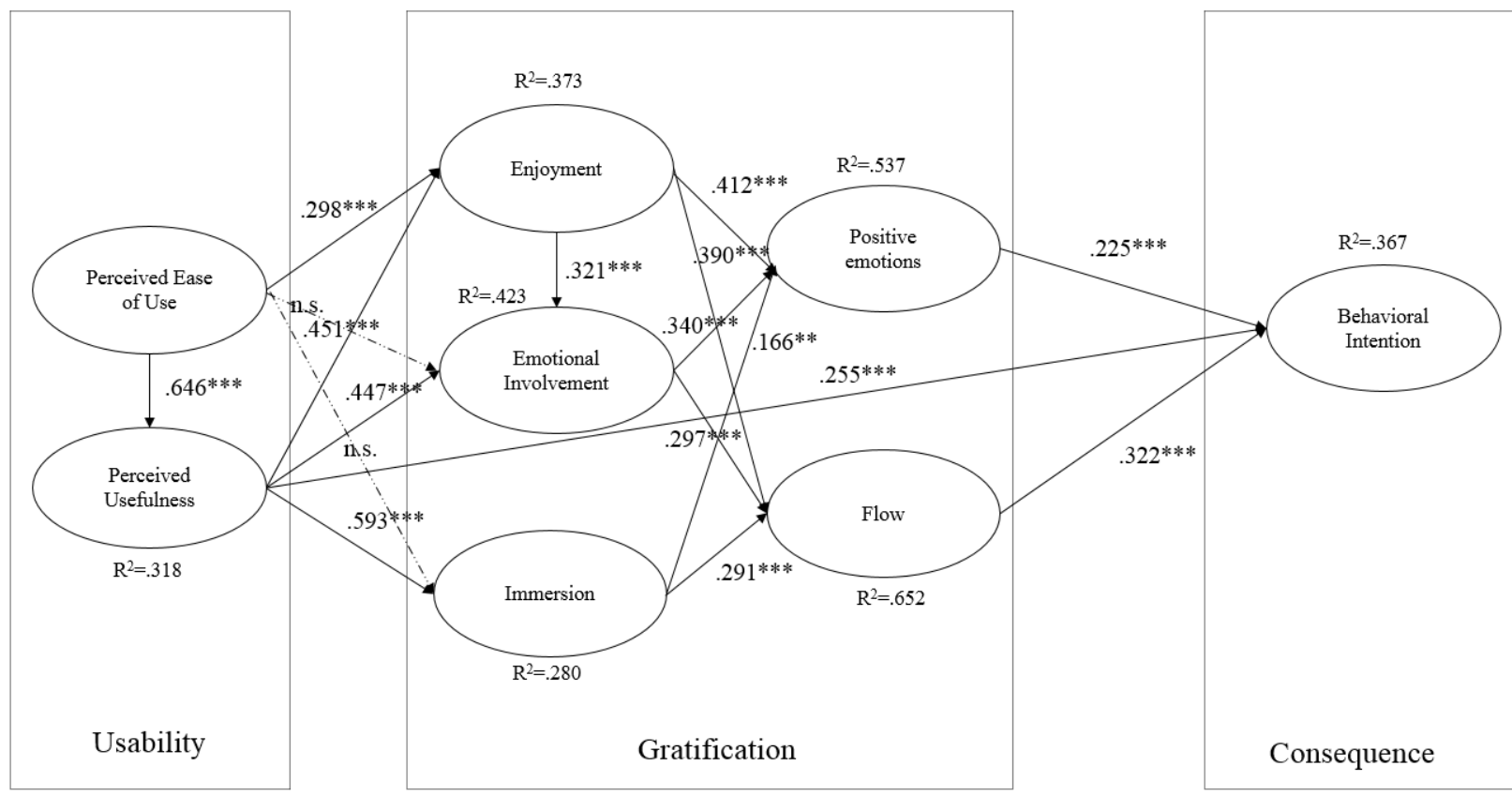

